\title{
Anthropometric characteristics and obesity among adolescents in the United Arab Emirates
}

A.A. Bin Zaal, ${ }^{1}$ J. Brebner, ${ }^{2}$ A.O. Musaiger ${ }^{3}$ and R. D'Souza ${ }^{3}$

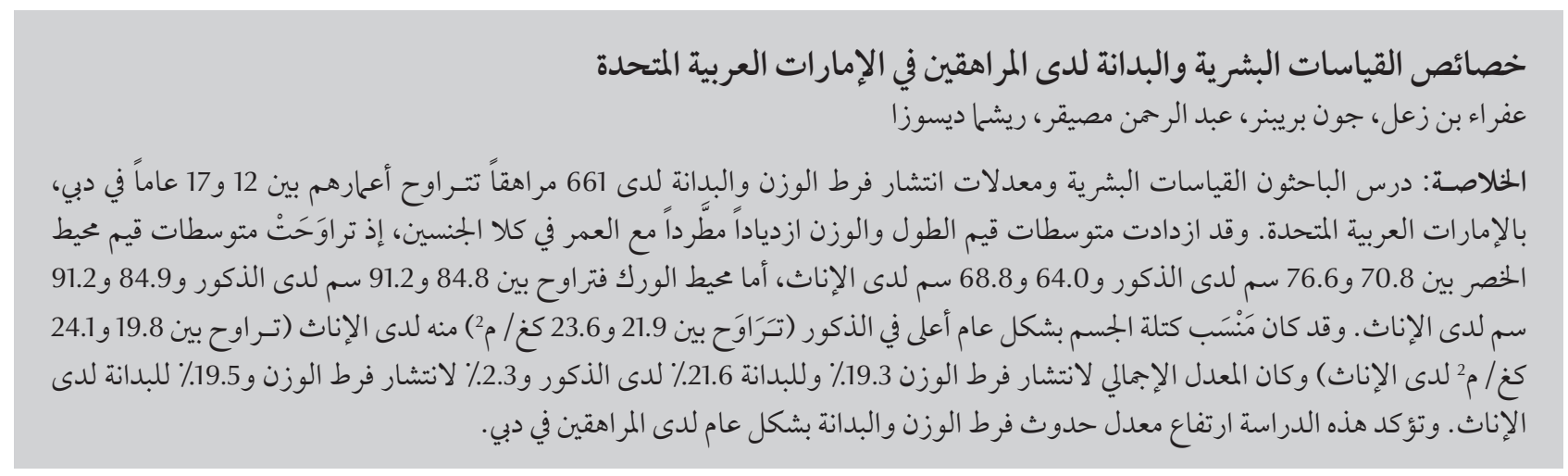

ABSTRACT Anthropometric measurements and the prevalence of overweight and obesity were studied in 661 adolescents aged 12-17 years from Dubai, United Arab Emirates. Mean values for height and weight increased steadily with age in both sexes. Mean values for waist circumference ranged from $70.8-76.6 \mathrm{~cm}$ in males and 64.0-68.8 cm in females. Hip circumference varied from 84.8-91.2 cm in males and 84.9-91.2 cm in females. Body mass index was generally higher in males than in females (range $21.9-23.6 \mathrm{~kg} / \mathrm{m}^{2}$ and $19.8-24.1 \mathrm{~kg} / \mathrm{m}^{2}$ respectively). The overall prevalence of overweight and obesity was $19.3 \%$ and $21.6 \%$ in males and $12.3 \%$ and $19.5 \%$ in females. This study confirms the high incidence of overweight and obesity in Dubai adolescents.

Caractéristiques anthropométriques et obésité chez les adolescents aux Émirats arabes unis

RÉSUMÉ Les mesures anthropométriques et la prévalence du surpoids et de l'obésité ont été étudiées chez 661 adolescents de Dubaï (Émirats arabes unis), âgés de 12 à 17 ans. Les valeurs moyennes pour la taille et le poids augmentaient de façon régulière avec l'âge pour les deux sexes. Les valeurs moyennes pour le tour de taille se situaient entre 70,8 et 76,6 cm chez les garçons et 64,0 et $68,8 \mathrm{~cm}$ chez les filles. Les mesures du tour de hanches variaient de 84,8 à 91,2 cm chez les adolescents et de 84,9 à 91,2 cm chez les adolescentes. L'indice de masse corporelle était généralement plus élevé chez les garçons que chez les filles (extrêmes 21,9-23,6 kg par m² et 19,8-24,1 kg par m², respectivement). La prévalence globale du surpoids et de l'obésité était de 19,3\% et 21,6\% chez les sujets de sexe masculin et de 12,3\% et 19,5\% chez les sujets de sexe féminin. La présente étude confirme I'incidence élevée du surpoids et de l'obésité chez les adolescents à Dubaï. 


\section{Introduction}

Due to its high economic growth, the United Arab Emirates (UAE) has evolved into one of the most dynamic and vibrant economies in the region and globally [1]. However, in recent times the UAE has started to experience high rates of obesity and diabetes [2]. Studies in this region indicate that changes in social and lifestyle factors as a result of improved socioeconomic status have resulted in an overall prevalence of obesity of about $35.7 \%$ among male university students [3]. A high prevalence of overweight and obesity in children aged 5-17 years has been documented too in the UAE [4]. It indicates that the frequency of obesity among UAE youth is higher than the published international data, which has profound public health implications for UAE adolescents [5]. The reasons cited for the high level of obesity are physical inactivity and unhealthy diets [6].

Studies in various countries have shown an increase in the prevalence of overweight and obesity among children in recent years and have given rise to concern about children's health and well-being [7]. Childhood and adolescent obesity tends to extend into adulthood and predisposes the individual to chronic disease in later life. The health and nutritional status of an individual is reflected in their body composition and among adolescents, the parameters used to assess body composition are weight, height, body mass index (BMI) and waist-hip ratio (WHR) [8]. BMI is easy to determine and has been considered as the gold standard for defining overweight and obesity, and has been correlated with percentage body fat [9]. Although previous studies have been carried out to determine the prevalence of obesity in the UAE $[4,5]$ there have been no measures of waist circumference (WC), hip circumference (HC) and WHR which provide a measure of fat distribution. In addition, these studies targeted the UAE adolescent population in general, while data on adolescents in Dubai emirate are lacking. Identifying obesity in adolescents provides an opportunity for earlier intervention with the goal of limiting the progression of abnormal weight gain that is a risk for obesity-related morbidity. The present study was therefore an attempt to obtain information regarding the level of overweight and obesity in the adolescent population in Dubai, UAE.

\section{Methods}

\section{Sample}

The study population included male and female students of UAE nationality aged 12 to 17 years from Dubai emirate. A representative sample of $5 \%$ of the total $\mathrm{Du}-$ bai adolescent school population (661 students, 324 males and 337 females) was selected by means of a multistage stratified random sampling technique in schools and stratified by sex and type of school (preparatory and secondary).

Dubai was first divided into 2 administrative areas (Bur Dubai and Deira). Then 3 preparatory and 3 secondary schools for each sex were selected by a simple random method for each area. One class from each educational level ( 3 for preparatory and 3 for secondary) were then selected from each school by a simple random method. Only adolescents of UAE nationality were included in the study. Students' reported age and date of birth were verified against the school records, which in turn were based on birth certificates.

The study was approved by the research ethics committee of the Ministry of Health, Dubai Medical District. All adolescents, parents and teachers were clearly informed about the purpose and content of the study and written consent was obtained from parents.

\section{Anthropometric measurements}

Weight and height were measured using standard procedures [10]. Weight was measured to the nearest $0.1 \mathrm{~kg}$ using an electronic portable scale (Seca). To ensure accuracy the scale was checked for zero reading before each weighing and calibrated with a known weight on the morning of each data collection. Student height was measured, in the standing position without shoes and socks, to the nearest $0.1 \mathrm{~cm}$ using a portable stadiometer attached to the Seca weighing scale. From these measurements the BMI (weight in kilograms divided by height in meters squared) was computed. The BMI was computed for each age and sex. Overweight was defined as BMI 85 th to $<95$ th percentile for age and obesity as BMI $\geq 95$ th percentile for age according to World Health Organization criteria [11].

WC was measured with a measuring tape at the level of the natural waist, i.e. the midpoint between the lower margin of the ribs (costal margin) and the superior and inferior iliac spine (iliac crest). $\mathrm{HC}$ was the maximum circumference around the buttocks at the posterior and the symphysis pubis at the anterior. From these measurements WHR was calculated.

\section{Analysis}

Statistical analysis was performed using SPSS software, version 9.0.

\section{Results}

The anthropometric characteristics and body composition in male and female Dubai adolescents are summarized in Tables 1 and 2 respectively. The mean values for height and weight increased with age in both sexes although some decrease in height and weight occurred in males at 16 years (decreasing by $1.2 \mathrm{~kg}$ and $1.5 \mathrm{~cm}$ respectively) and in females at 15 years of age (decreasing by $1.6 \mathrm{~kg}$ and $0.5 \mathrm{~cm}$ respectively). The variation in weight was greater than the variation in height in both sexes and the weights and heights of males were greater than females. 


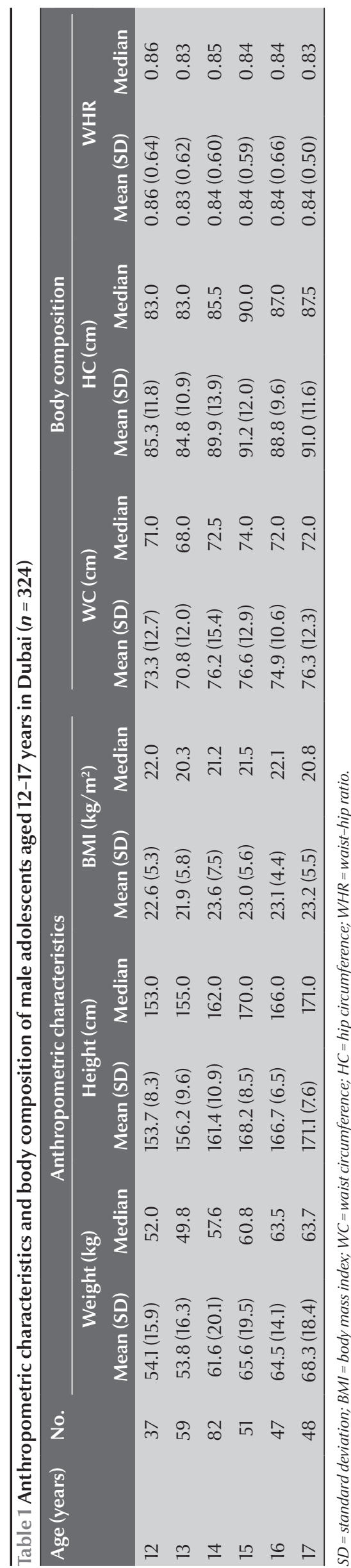

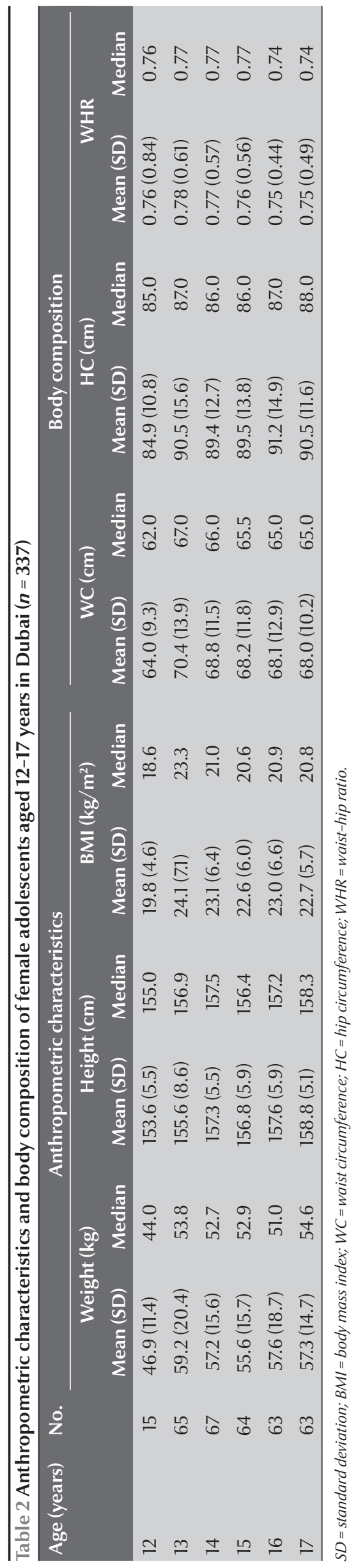

The mean values for $\mathrm{WC}$ varied from 70.8 to $76.6 \mathrm{~cm}$ in males and 64.0 to $70.4 \mathrm{~cm}$ in females between 12 and 17 years. However the WC for males was greater than the females. The same was true for $\mathrm{HC}$, varying from 84.8 to 91.2 $\mathrm{cm}$ in males and 84.9 to 91.2 $\mathrm{cm}$ in females between 12 and 17 years. It is clear from the mean values that both males and females of the same age had the same hip circumference. The WHR showed a decrease in males from 12 to 13 years ( 0.86 and 0.83 respectively) then become stable from 14 to 17 years, but was quite unstable in females.

BMI ranged from 21.9 to $23.6 \mathrm{~kg} / \mathrm{m}^{2}$ and 19.8 to 24.1 $\mathrm{kg} / \mathrm{m}^{2}$ in males and females respectively. At each age group, except for age 13 years, BMI was slightly higher in males than in females.

The prevalence of overweight and obesity in male and females is shown in Table 3. The overall prevalence of overweight and obesity was $19.3 \%$ and $21.6 \%$ respectively in males and $12.3 \%$ and $19.5 \%$ respectively in females. The rate of overweight was highest in males at 16 years of age (25.5\%) but showed a decline the following year (16.7\%). The prevalence of obesity was highest at 12 and 14 years of age $(32.4 \%$ and $30.5 \%)$ and declined after that. In females, overweight was most prevalent at 17 years of age (19.0\%) and was lowest at 12 years of age $(6.7 \%)$. The prevalence of obesity was highest at 13 years of age (35.4\%) followed by a gradual decline from 14 to 17 years of age (from $25.4 \%$ to $12.7 \%)$. 


\begin{tabular}{|c|c|c|c|c|c|c|c|c|}
\hline \multirow[t]{3}{*}{ Age (years) } & \multicolumn{4}{|c|}{ Males $(n=324)$} & \multicolumn{4}{|c|}{ Females $(n=337)$} \\
\hline & \multicolumn{2}{|c|}{ Overweight } & \multicolumn{2}{|c|}{ Obese } & \multicolumn{2}{|c|}{ Overweight } & \multicolumn{2}{|c|}{ Obese } \\
\hline & No & $\%$ & No. & $\%$ & No. & $\%$ & No. & $\%$ \\
\hline 12 & 9 & 24.3 & 12 & 32.4 & 1 & 6.7 & 2 & 13.3 \\
\hline 13 & 8 & 13.6 & 13 & 22.0 & 10 & 15.4 & 23 & 35.4 \\
\hline 14 & 13 & 15.9 & 25 & 30.5 & 5 & 7.5 & 17 & 25.4 \\
\hline 15 & 10 & 19.6 & 10 & 19.6 & 7 & 10.9 & 11 & 17.2 \\
\hline 16 & 12 & 25.5 & 6 & 12.8 & 9 & 14.3 & 8 & 12.7 \\
\hline 17 & 8 & 16.7 & 6 & 12.5 & 12 & 19.0 & 8 & 12.7 \\
\hline Total & 60 & 19.3 & 72 & 21.6 & 44 & 12.3 & 69 & 19.5 \\
\hline
\end{tabular}

\section{Discussion}

The findings of this study confirm earlier reports of a high prevalence of overweight amongst UAE adolescents [4]. This agrees with reports that the prevalence of childhood obesity in the $\mathrm{UAE}$ is increasing dramatically when compared with data from 1999[5], already surpassing the high levels of obesity that have been found among children and adolescents in the United States and Europe [12]. Comparison of levels of obesity between the sexes indicates that that obesity was slightly higher among males than females, irrespective of the criteria used to assess their weight status. These results are in contrast to reports from other Gulf countries such as Kuwait where obesity was more prevalent in females than males [13]. This sex difference may be due to higher prevalence of dieting for weight-control purposes in the UAE among females than among the males [14]. The higher BMI observed in females at 13 years of age could be due to the onset of puberty in the females, although no pubertal staging was done in the present study. However, a previous study in the UAE indicated that the mean age of menarche in females in the UAE was 12.68 (SD 1.27) years [15]. Sexual development influences anthropometric measurements and body composition during adolescence [11], and age and sexual maturation are important factors producing variations in BMI [16].
Some important anthropometric indicators of regional body fat distribution include WHR, WC and HC. Waist circumference is easy to determine and is the best measure of fat distribution for children and adolescents, being the least affected by sex, race and overall adiposity [17]. Body fat deposition could be either truncal fat or peripheral fat [18] and it has long been noted that people differ with respect to the location of fat [19]. Reports indicate that in males, fat typically accumulates in the upper segment of the body (truncal), both subcutaneously and intra-abdominally, whereas in females, adipose tissue accumulates subcutaneously over the thighs [20]. These are in accordance to our findings where males had greater WC values compared with the females. In addition, the finding that males had higher WHR values than females was consistent with previous reports for Bahraini adolescents [21]. It is evident that approximately $7.0 \%$ of males and $12.0 \%$ females had WC values below the sex and age specific cut-offs [22], which could be due to deposition of fat in the peripheral parts. Studies on the distribution of body fat from childhood to adulthood indicated that in both sexes the WHR decreased and BMI increased with age from childhood to 18 years, and then both increased from age 18 to 30 years [23]. In addition, mean values of WHR which is a measure of regional fat distribution was always lower than 0.8 in females and 0.9 in males, indicating a healthy body fat distribution, according to body fat distribution criteria [24].

Compared to other Gulf adolescents, the levels of obesity in males in this study were similar to those reported for adolescents aged 12-17 years in Bahrain, although fewer females were obese [25]. However, the prevalence of overweight was nearly 2-3 times higher in both sexes compared to their Bahraini counterparts. Compared to their Kuwaiti counterparts aged 12-14 years, the prevalence of obesity amongst $\mathrm{Du}-$ bai adolescents was 1.5-2 times higher [26].

Although this study was carried out on a small proportion of the $\mathrm{Du}$ bai adolescent population, it clearly demonstrates the high prevalence of overweight and obesity in this vulnerable group. Hence this information may help target high-risk individuals. However, further studies targeting a higher proportion of adolescents will give a greater insight into the epidemic of obesity among Dubai adolescents. Overweight is due to an imbalance between dietary intake and energy expenditure, but the exact reason for the imbalance among children is not clear [27]. This increase in levels of obesity appears to have occurred during recent decades in the Middle East countries [28] and sedentary lifestyle and diet have often been cited for overweight and obesity in this region [29]. Several disorders have been linked to overweight in childhood and of particular 
concern has been the potential increase in type 2 diabetes mellitus and impaired glucose tolerance.

Although it is not yet confirmed what intervention programmes are effective of reducing this incidence of overweight and obesity, changes in the social, economic and physical environment need to be addressed. In addition, changes in the existing dietary habits both at home and in the places where the adolescents interact are essential. Attention should be given to strategies aimed at preventing obesity in the UAE population.

\section{References}

1. UN Resident Coordinator report of 2005 for the United Arab Emirates. New York, United Nations, 2006.

2. Mackay J, Mensah G. The atlas of heart disease and stroke. Geneva, World Health Organization, 2004.

3. Musaiger AO, et al. Lifestyle factors associated with obesity among male university students in the United Arab Emirates. Nutrition and Food Science, 2003, 33:145-147.

4. Malik M, Bakir A. Prevalence of overweight and obesity among children in the United Arab Emirates. Obesity Review, 2007, 8:15-20.

5. Al-Haddad FH et al. Childhood obesity in United Arab Emirates schoolchildren: A national study. Annals of Human Biology, 2005, 32:72-79.

6. Diabetes is pandemic in the Mid East: World Health Organisation. AME Info, Monday, January 19, 2004 (http://www. ameinfo.com/33714.html, accessed 6 July 2009).

7. Flegel KM et al. Overweight in children: definitions and interpretation. Health Education Research, 2006, 21:755-760.

8. Musaiger AO et al. Obesity among secondary school students in Bahrain. Nutrition and Health, 1993, 9:25-32.

9. Bhansali A et al. Does body mass index predict overweight in native Asian Indians? A study from a North Indian population. Annals of Nutrition and Metabolism, 2006, 50:66-73.

10. Fidanza F. Anthropometric methodology. In: Fidanza F, ed. Nutritional assessment: a manual for population studies. London, Chapman and Hall, 1991:1-43.

11. Physical status: the use and interpretation of anthropometry. Report of a WHO Expert Committee. Geneva, World Health Organization 1995 (WHO Technical Report Series, No. 854).

12. Westerbeek H, Smith A. Corporate social responsibility and community health in the UAE: the case of the Al Jazira Sport and Health Foundation. Middle East Journal of Business, 2005, 1:1.

13. Al Mosa Z, Parkash P. Prevalence of overweight and obesity among Kuwaiti children and adolescents. Bahrain Medical bulletin, 2000, 22:123-127.

14. Neumark-Sztainer D et al. Sociodemographic and ersonal characteristics of adolescents engaged in weight loss and weight/muscle gain behaviors: who is doing what? Preventive Medicine, 1999, 28:40-50.

15. Badrinath $\mathrm{P}$ et al. Cultural and ethnic barriers in conducting research. Factors influencing menarche in the United Arab Emirates. Saudi Medical Journal, 2004, 25:1626-1630.
16. Daniels SR et al. The utility of body mass index as a measure of body fatness in children and adolescents: differences by race and gender. Pediatrics, 1997, 99:804-807.

17. Daniels SR et al. Utility of different measures of body fat distribution in children and adolescents. American Journal of Epidemiology, 2000, 152:1179-1184.

18. He Q et al. Trunk fat and blood pressure in children through puberty. Circulation, 2002, 105:1093-1098.

19. Sjostrom L. Morbidity and mortality of severely obese subjects. American Journal of Clinical Nutrition, 1992, 55:508S-515S.

20. Rössner $\mathrm{S}$ et al. Adipose tissue determinations in cadavers--a comparison between cross-sectional planimetry and computed tomography. International Journal of Obesity, 1990, 14:893-902.

21. Al-Sendi AM et al. Anthropometric and body composition indicators of Bahraini adolescents. Annals of Human Biology, 2003a; 30:367-379

22. Taylor RW et al. Evaluation of waist circumference, waist-to-hip ratio, and the conicity index as screening tools for high trunk fat mass, as measured by dual-energy X-ray absorptiometry, in children aged 3-19 y. American Journal of Clinical Nutrition, 2000, 72:490-495.

23. Casey VA et al. The distribution of body fat from childhood to adulthood in a longitudinal study population. Annals of $\mathrm{Hu}$ man Biology, 1994, 21:39-55

24. Martinez E et al. Percentiles of the waist-hip ratio in Cuban scholars aged 4.5 to 20.5 years. International Journal of Obesity and Related Metabolic Disorders, 1994, 18:557-560.

25. Al-Sendi AM et al. Prevalence of overweight and obesity among Bahraini adolescents: a comparison between three different sets of criteria. European journal of clinical nutrition, 2003b, 57:471-4.

26. Al-Isa AN. Body mass index, overweight and obesity among Kuwaiti intermediate school adolescents aged 10-14 years. European Journal of Clinical Nutrition, 2004, 58:1273-1277.

27. Ogden CL et al. Prevalence and trends in overweight among US children and adolescents 1999-2000. Journal of the American Medical Association, 2002, 288:1728-1732.

28. James PT. Obesity: the worldwide epidemic. Clinics in Dermatology, 2004, 22:276-280.

29. Musaiger AO. Overweight and obesity in the Eastern Mediterranean Region: can we control it? Eastern Mediterranean Health Journal, 2004, 10:789-793. 